\title{
Butylated Hydroxytoluene Induced Resistance Against Botryosphaeria dothidea in Apple Fruit
}

\author{
Yan Huang ${ }^{1}$, Cuicui Sun ${ }^{1}$, Xiangnan Guan', Sen Lian ${ }^{1}$, Baohua Li1 and Caixia Wang ${ }^{1 *}$ \\ ${ }^{1}$ Key Laboratory of Integrated Crop Pest Management of Shandong Province, College of Plant Health and Medicine, \\ Qingdao Agricultural University, Qingdao, China, ${ }^{2}$ Knight Cancer Institute, Oregon Health \& Science University, Portland, OR, \\ United States
}

\section{OPEN ACCESS}

Edited by:

Santanu Basu,

Swedish University of Agricultural

Sciences, Sweden

Reviewed by:

Koushik Mazumder

National Agri-Food Biotechnology

Institute, India

Wenxing $X u$,

Huazhong Agricultural University,

China

*Correspondence: Caixia Wang

cxwang@qau.edu.cn

Specialty section:

This article was submitted to

Food Microbiology,

a section of the journa

Frontiers in Microbiology

Received: 26 August 2020

Accepted: 03 December 2020

Published: 14 January 2021

Citation:

Huang Y, Sun C, Guan X, Lian S,

Li B and Wang C (2021) Butylated

Hydroxytoluene Induced Resistance

Against Botryosphaeria dothidea

in Apple Fruit.

Front. Microbiol. 11:599062. doi: 10.3389/fmicb.2020.599062
Apple ring rot caused by Botryosphaeria dothidea is an important disease in China, which leads to serious economic losses during storage. Plant activators are compounds that induce resistance against pathogen infection and are considered as a promising alternative strategy to traditional chemical treatment. In the present study, butylated hydroxytoluene $(\mathrm{BHT})$, a potential plant activator, was evaluated for its induced resistance against $B$. dothidea in postharvest apple fruits. The physiological and molecular mechanisms involved in induced resistance were also explored. The results showed that $\mathrm{BHT}$ treatment could trigger strong resistance in apple fruits against B. dothidea, and the optimum concentration was $200 \mu \mathrm{mol} \mathrm{L}^{-1}$ by immersion of fruits. BHT treatment significantly increased the activities of four defensive enzymes and alleviated lipid peroxidation by increasing antioxidant enzyme activities. In addition, salicylic acid (SA) content was enhanced by BHT treatment as well as the expression of three SA biosynthesis-related genes (MdSID2, MdPAD4, and MdEDS1) and two defense genes (MdPR1 and MdPR5). Our results suggest that BHT-conferred resistance against $B$. dothidea might be mainly through increasing the activities of defense-related enzymes and activating SA signaling pathway, which may provide an alternative strategy to control apple ring rot in postharvest fruits.

Keywords: butylated hydroxytoluene, apple fruit, induced resistance, Botryosphaeria dothidea, defense-related enzyme, salicylic acid signaling

\section{INTRODUCTION}

Apple (Malus domestica Borkh.) is one of the most important fruit and is widely consumed worldwide. However, the apple fruit is susceptible to pathogenic fungi, one of which is Botryosphaeria dothidea (Tang et al., 2012). B. dothidea is a plant hemi-biotrophic fungi and causes apple ring rot, a severe disease that reduces the yield and quality of apple, especially in China. Infected fruits show soft, sunken lesions with alternating tan and brown rings. $B$. dothidea infects fruits at the growth stage and causes fruit rot during the ripening or in the postharvest period (Zhang Q. M. et al., 2016), making it difficult to control apple ring rot. In addition, B. dothidea also infects apple tree branches, resulting in warts, canker, necrotic bark lesions, and even the death of the branches (Zhao et al., 2016).

Currently, the main strategy to control apple ring rot is the eradication of the fungal inoculum combined with application of bagging technology and scheduled spraying of protective fungicides 
(Zhao et al., 2016). As the cost of bagging is increasing yearly, the baggless cultivation of apple has become an inevitable trend in China. However, apple fruit ring rot is the key problem that remains to be solved in baggless cultivation (Zhao et al., 2016; Yu et al., 2018). Furthermore, issues associated with chemical residue, fungicide resistance in pathogens, and serious environmental pollution have motivated to develop new, effective, and eco-friendly agents for the control of apple ring rot (Fan et al., 2016, 2018).

Plant activators that induce plant defense response have attracted considerable interest due to their broad-spectrum resistance and long-term disease control while reducing the environmental burden (Yang et al., 2015; Liu et al., 2019). As an alternative strategy to traditional chemical treatment, the application of activators has gained increasing attention ( $\mathrm{Yu}$ et al., 2014; Zhang Y. et al., 2016). The plant activators include physical, biological, and chemical inducers, while most are compounds. Complex signaling networks, such as the pathways mediated by salicylic acid (SA), jasmonic acid (JA), and ethylene (ET), are activated by plant activators, leading to plant defense response (Van Bockhaven et al., 2015; Yu et al., 2019). SA-mediated signaling plays important roles in fighting against (hemi)biotrophic pathogens (Glazebrook, 2005) as well as in the activation of robust systemic resistance marked by the increased expression of many defense proteins including pathogenesis-related (PR) proteins. In contrast, JA- and/or ETmediated signaling is mainly involved in plant defense against necrotrophic pathogens.

As metabolic by-products in plants, reactive oxygen species (ROS) play a pivotal role in the regulation of plant defense response against pathogen invasion (Torres, 2010; Wang et al., 2014). However, ROS produced in excess can cause oxidative damage and induce membrane lipid peroxidation in the cellular environment (Marschall and Tudzynski, 2016). To protect cells from oxidative damage, plants employ a complex ROSantioxidative system to scavenge harmful ROS. The main scavenging mechanism includes enzymatic antioxidants and metabolites that facilitate their degradation (Mittler, 2002).

In the previous work, we demonstrated that Streptomyces rochei A-1 could induce resistance against $B$. dothidea infection in postharvest apple fruit and did not affect the external and internal fruit appearance (Zhang Q. M. et al., 2016). It was recently found that butylated hydroxytoluene (BHT) was one of the main metabolites of $S$. rochei A-1 and that low concentration of BHT could effectively inhibit the postharvest apple fruit decay caused by $B$. dothidea. However, low concentration of BHT has no effect on mycelial growth and spore germination of $B$. dothidea (Yu et al., 2018), suggesting other possible mechanisms of BHT in inhibiting postharvest decay in apple fruits. Moreover, BHT could inhibit postharvest gray mold caused by Botrytis cinerea and bitter rot caused by Colletotrichum gloeosporioides (data not published). As a synthetic phenolic antioxidant, BHT has been widely used in foods and food-related products, such as packing (Babich, 1982). Furthermore, BHT could activate several antioxidases and regulate endogenous nitric oxide against abiotic stress conditions in Haematococcus pluvialis (Zhao et al., 2018).
In this study, we set out to investigate the effectiveness of $\mathrm{BHT}$ on the control of apple ring rot caused by $B$. dothidea in postharvest apple fruit. The possible mechanisms of action underlying BHT-induced resistance to $B$. dothidea and the association with the SA signaling pathway in apple fruits were also explored. Our results suggested BHT treatment as a promising strategy to protect fruits from pathogen infection.

\section{MATERIALS AND METHODS}

\section{Butylated Hydroxytoluene, Fungal Pathogen, and Fruit Materials}

Butylated hydroxytoluene was purchased from Sigma-Aldrich (St. Louis, United States). The stock solution (1 M in methanol) was filtered through a $0.22-\mu \mathrm{m}$ filter for sterilization and stored at $-20^{\circ} \mathrm{C}$. The working concentration of BHT in this study was 0 (0.1\% methanol as control), 50, 100, 200, and $500 \mu \mathrm{mol} \mathrm{L}^{-1}$.

In this study, the fungal pathogen Botryosphaeria dothidea LXS030101, which was used in our previous study (Zhang Q. M. et al., 2016), was isolated from infected "Red Fuji" fruits with typical apple ring rot symptoms. The pathogen was maintained on potato dextrose agar (PDA: the extract of $200 \mathrm{~g}$ of potato, $20 \mathrm{~g}$ of glucose, and $15 \mathrm{~g}$ of agar in $1 \mathrm{~L}$ of water) at $4^{\circ} \mathrm{C}$ and was revived on PDA plates for 3 days to obtain the culture. Conidia were harvested from young apple fruits following the method described by Leng et al. (2009). Spore concentration was determined by a hemocytometer and adjusted with sterile distilled water to the concentration of $1 \times 10^{5}$ spores $\mathrm{ml}^{-1}$.

Apple (cv. "Fuji") fruits were harvested at a commercial mature stage from a commercial orchard in Qingdao, China. For this study, fruits with uniform shape, size, and no physical injuries were selected. Before treatment, fruits were surface disinfected with $2 \%(\mathrm{v} / \mathrm{v})$ sodium hypochlorite for $2 \mathrm{~min}$, washed with tap water, and then air-dried for use in the experiments.

\section{Induction of Apple Fruit Resistance Against Botryosphaeria dothidea by Butylated Hydroxytoluene}

Prior to pathogen inoculation, apple fruits were pre-treated with BHT according to the previous procedure with some modifications (Yang et al., 2017). Briefly, apple fruits were immersed in the BHT solution for $15 \mathrm{~min}$ at different concentrations $\left(0,50,100,200\right.$, and $\left.500 \mu \mathrm{mol} \mathrm{L}{ }^{-1}\right)$. Then, all fruits were taken out, air-dried for $2 \mathrm{~h}$ at room temperature, and stored in plastic boxes. After $48 \mathrm{~h}$ of incubation at $25^{\circ} \mathrm{C}$, three uniform wounds ( $5 \mathrm{~mm}$ wide and $3 \mathrm{~mm}$ deep) around the apple equator were punctured with a sterile borer (Zhang Q. M. et al., 2016). Each wound was inoculated with $10 \mu \mathrm{l}$ of $B$. dothidea spore suspension at $1 \times 10^{5}$ spores $\mathrm{ml}^{-1}$. All treated fruits were incubated at $25^{\circ} \mathrm{C}$ and high relative humidity of $90-95 \%$. Disease severity was expressed by disease incidence and lesion areas, which were recorded at 3, 5, and 7 days post inoculation (dpi). Disease incidence was calculated as the percentage of infected wounds, and lesion diameter was measured for infected wounds only. The experiment was 
conducted three times in triplicates with 10 fruits in each replicate group.

\section{Treatment of Apple Fruit and Sample Collection}

Apple fruits were divided into two groups, immersed in $0 \mu \mathrm{mol} \mathrm{L}{ }^{-1}\left(0.1 \%\right.$ methanol as control) or $200 \mu \mathrm{mol} \mathrm{L} \mathrm{L}^{-1}$ of BHT solution, air-dried for $2 \mathrm{~h}$, and then stored at $25^{\circ} \mathrm{C}$ with high relative humidity. Sample collection was performed following the method of Zheng et al. (2011). Peels from the fruit equator area were excised and cut into small pieces at time points $0,0.5,1,2,3,5$, and 7 days after treatment. Each treatment included three replicates, and each replicate consisted of five fruits. The excised tissues from five fruits were mixed and encased in aluminum foil, snap frozen in liquid nitrogen, and then stored at $-86^{\circ} \mathrm{C}$ until further biochemical assays and gene expression analysis. All the experiments were repeated thrice.

\section{Determination of Defensive Enzyme Activities}

Phenylalanine ammonia lyase (PAL; EC 4.3.1.5), polyphenol oxidase (PPO; EC 1.10.3.1), $\beta$-1,3-glucanase (GLU; EC 3.2.1.58), and chitinase (CHI, EC 3.2.1.14) were assayed according to the method of Zhang Q. M. et al. (2016), Zhang Y. et al. (2016). Fruit tissues $(0.5 \mathrm{~g})$ were homogenized with $5 \mathrm{ml}$ of $100 \mathrm{mmol} \mathrm{L}^{-1}$ of phosphate-buffered saline (PBS; pH 6.88.8) containing $1 \%(\mathrm{w} / \mathrm{v})$ polyvinylpyrrolidone (PVP) for PPO and PAL, and $50 \mathrm{mmol} \mathrm{L}^{-1}$ of sodium acetate buffer $(\mathrm{pH}$ 5.0) for GLU and CHI. The homogenate was centrifuged for $15 \mathrm{~min}$ at $12,000 \mathrm{~g}$ at $4^{\circ} \mathrm{C}$, and the supernatants were used to determine the enzyme activities. The activities of PAL, PPO, GLU, and CHI were calculated on the basis of fresh weight (FW), which were expressed as $\mathrm{U} \mathrm{g}^{-1} \mathrm{FW}$. All measurements were performed in triplicate with samples collected from three biological replicates.

\section{Determination of Antioxidant Enzyme Activities and Lipid Peroxidation}

To determine the activities of main antioxidant enzymes including catalase (CAT, EC 1.11.1.6), peroxidase (POD, EC 1.11.1.7), and superoxide dismutase (SOD, EC 1.15.1.1), $0.5 \mathrm{~g}$ of fruit tissues was homogenized with $5 \mathrm{ml}$ of $100 \mathrm{mmol}$ $\mathrm{L}^{-1}$ PBS (pH 7.0) containing 1\% PVP (w/v). The CAT Assay Kit A007, POD Assay Kit A084, and SOD Assay Kit A001 (Nanjing Jiancheng Bioengineering Institute, Nanjing, China) were used to measure the enzyme activities, following the protocol provided by the manufacturers. The final activity was expressed as $\mathrm{U} \mathrm{g}^{-1} \mathrm{FW}$. Three biological replicates were used in each treatment.

To analyze the lipid peroxidation in apple fruits, four treatment groups were designed as follows: (i) control, fruits treated with $0.1 \%$ methanol; (ii) BHT, fruits treated with $200 \mu \mathrm{M}$ of BHT solution; (iii) pathogen, fruits treated with $0.1 \%$ methanol followed by $B$. dothidea inoculation; (iv) BHT + pathogen, fruits treated with $200 \mu \mathrm{mol} \mathrm{L} \mathrm{L}^{-1}$ of BHT followed by
B. dothidea inoculation. Fruit tissues were collected at various intervals $(0,1,2,3,4,5$, and $7 \mathrm{dpi})$ as the description of Zhang Y. et al. (2016). Malondialdehyde (MDA) content was measured to determine lipid peroxidation in fruit tissues with an MDA Assay Kit A003 (Nanjing Jiancheng Bioengineering Institute, Nanjing, China). The MDA content was expressed as mmol per $\mathrm{kg}$ of FW. Three replicates were carried out in this experiment.

\section{Analysis of Gene Expression by Quantitative Real-Time PCR}

Spin column plant total RNA purification kit was used to extract total RNA from fruit tissues (Sangon Biotech, Shanghai, China). After quantification by micro spectrophotometry, a total of $2 \mu \mathrm{g}$ of RNA was used for first-strand cDNA synthesis, using the Prime Script RT Reagent Kit with gDNA Eraser (Takara, Dalian, China). qRT-PCR was performed using SYBR Premix Ex Taq kit (Takara, Dalian, China) according to the protocol provided by the manufacturer. Primers used for qRT-PCR are listed in Table $\mathbf{1 .}$ The qRT-PCR thermal cycling program was as follows: initial denaturation for $30 \mathrm{~s}$ at $95^{\circ} \mathrm{C}, 40$ cycles of $5 \mathrm{~s}$ at $95^{\circ} \mathrm{C}, 15 \mathrm{~s}$ at $59^{\circ} \mathrm{C}$ (or $58^{\circ} \mathrm{C}$ or $56^{\circ} \mathrm{C}$ ), and $15 \mathrm{~s}$ at $72^{\circ} \mathrm{C}$. Elongation factor 1-a (EF1a) was used as a reference gene, and the relative gene expression was normalized to the EF1a Ct value according to the formula $2^{-\Delta \Delta C t}$. All experiments were carried out with at least three biological replicates.

\section{Determination of Salicylic Acid Content}

Salicylic acid and SA glucoside (SAG) were extracted and measured from $0.3 \mathrm{~g}$ of fresh fruit tissue, as described by the previous method with some modifications (Verberne et al., 2002). The sample was homogenized with $1 \mathrm{ml}$ of $90 \%$ methanol, and anisic acid was added as an internal standard. The homogenate was centrifuged at $6,000 \mathrm{~g}$ for $5 \mathrm{~min}$, and the supernatant was collected and concentrated with nitrogen. Trichloroacetic acid was added to a concentration of $1 \mathrm{~g} \mathrm{~L}^{-1}$. The sample was extracted three times with 1:1 ethylacetate:cyclohexane and used to detect the free SA. For SAG detection, $8 \mathrm{~mol}$ $\mathrm{L}^{-1}$ of $\mathrm{HCl}$ was added into the water phase collected from the abovementioned steps. The sample was boiled for $30 \mathrm{~min}$ and extracted as the abovementioned method. Samples were analyzed by an Agilent 1260 (Agilent Technologies, Palo Alto, CA, United States). SA and SAG contents were expressed as micrograms per kilogram of $\mathrm{FW}$, and the results were the average of four independent extractions. The experiment was repeated twice.

\section{Statistical Analysis}

All the experiments were implemented using a completely randomized design. The biochemical and gene expression analyses of fruit tissues for each treatment were conducted in triplicate at each sampling point. The data were expressed as the mean \pm standard deviation (SD). All data were subjected to analysis of variance (ANOVA) followed by Duncan's multiple range tests. Statistical significance was determined with a $P$ value of less than 0.05 . 
TABLE 1 | Specific primers used for quantitative real-time PCR to analyze gene expression.

\begin{tabular}{|c|c|c|c|}
\hline Primer name & Forward primer $5^{\prime} \rightarrow 3^{\prime}$ & Reverse primer $5^{\prime} \rightarrow 3^{\prime}$ & Annealing temperature $\left({ }^{\circ} \mathrm{C}\right)$ \\
\hline$M d E F 1 \alpha$ & ACATTGCCCTGTGGAAGTT & GTCTGACCATCCTTGGAAA & $59 / 58 / 56$ \\
\hline MdPR1 & GCAGCAGTAGGCGTTGGTCCCT & CCAGTGCTCATGGCAAGGTाা & 59 \\
\hline MdPR5 & AGCAGCTTCCCTCCTCGGC & CCCAGAAGCGACCAGACC & 58 \\
\hline MdPDF1.2 & ATGTITGGACTGATGTGGCAA & TCAACATCTGAAGTAGCAGAAG & 58 \\
\hline MdCOI1 & CTGACTTCCCTTAGGTACTTGTG & CAACTCGTCTCGGAGGAATCAA & 58 \\
\hline MdERF3 & TCCTTCAAAGCTCCGCTGACTT & CCAAGATGGTGCCTGGAAATCA & 58 \\
\hline MdCTR1 & AACTTGTCCATAGTCACGGAA & CCTITGCCACATCATATGCC & 58 \\
\hline MdSID2 & TTATACTTCATTCCGCTGCT & GCCTCTAATIICTITGTATGCT & 56 \\
\hline MdEDS1 & GAGCTAGACAATGCCTTCGT & AGTATCCCTCATTGTGCTCGT & 58 \\
\hline MdPAD4 & GCTTCACCGTAAGTTACTCG & CAAGAAACTCGCAACTGTC & 58 \\
\hline
\end{tabular}

\section{RESULTS}

\section{Induction of Disease Resistance in Apple Fruit Against Botryosphaeria dothidea by Butylated Hydroxytoluene}

The effectiveness of BHT for controlling apple ring rot in fruits was significantly affected by the concentrations of BHT (Figure 1). In the control fruits treated with $0.1 \%$ methanol, brown lesions with large zones appeared on the inoculation site and developed rapidly (Figure 1A). In contrast, the development of ring rot symptoms was significantly inhibited by BHT treatment, as indicated by the lower disease incidence and smaller lesion diameter in BHT-treated fruits compared with control until 7 dpi (Figures 1B,C). Meanwhile, BHT at the concentration of $200 \mu \mathrm{mol} \mathrm{L}^{-1}$ showed the strongest effect on mitigating ring rot development (Figure 1A). Although disease incidence and lesion diameter increased from 3 to $7 \mathrm{dpi}$ in all treatments, $200 \mu \mathrm{mol} \mathrm{L}^{-1}$ of BHT treatment decreased disease incidence by $25.56 \%$ and lesion diameter by $78.22 \%$ as compared with control at 7 dpi (Figures 1B,C).

\section{Effect of Butylated Hydroxytoluene on Defensive Enzyme Activities in Apple \\ Fruit}

To analyze whether BHT treatment was able to increase the defensive enzyme activities, PAL, PPO, GLU, and CHI activities were measured in apple fruits with or without BHT treatment. As shown in Figure 2, four defensive enzyme activities in the control apple fruits exhibited no obvious changes during the storage, whereas the enzyme activities in BHT-treated fruits increased significantly $(P<0.05)$ with varying patterns. PAL and PPO activities in BHT-treated fruits were remarkably enhanced at 2 days and then peaked at 5 and 3 days, which were 1.7 -fold and 2.2-fold higher than those in the control fruits, respectively (Figures 2A,B). The activities of PAL and PPO in BHT-treated fruits then dropped sharply. The PPO activity decreased to the control level at 7 days, whereas the PAL activity in BHT-treated fruits was significantly $(P<0.05)$ higher than that in the control fruits during the storage (Figures 2A,B).

For CHI and GLU, BHT-treated fruits exhibited significantly higher enzyme activities from day 1 onward as compared with the control fruits (Figures 2C,D). Particularly, in BHTtreated fruits, GLU activity increased continuously and peaked at 7 days, which was 1.7 times more than that of the control (Figure 2C). Meanwhile, $\mathrm{CHI}$ activity reached the highest level at 5 days, which was 2.5 -fold higher than that in the control fruits (Figure 2D). These results suggested that BHT could enhance disease resistance against Botryosphaeria dothidea by heightening the activities of defensive enzymes PAL, PPO, GLU, and CHI.

\section{Effect of Butylated Hydroxytoluene on Antioxidant Enzyme Activities and Lipid Peroxidation in Apple Fruit}

To obtain more insights into the mechanisms of BHT in induced resistance against $B$. dothidea, antioxidant enzyme activities and lipid peroxidation were determined during apple fruit storage, with or without BHT treatment. In the control fruits, the antioxidant enzymes (CAT, POD, and SOD) activities showed no obvious changes throughout the experiment period; however, three enzyme activities markedly enhanced in BHT-treated fruits (Figures 3A-C). CAT activity increased slowly and reached the maximum levels at 3 days in fruits treated with BHT, which was 2.1-fold higher than that in the control fruits. Similarly, BHT treatment resulted in an evident increase of POD activity, and the maximum fold increase was reached at 2 days (3.6-fold higher than that in the control fruits). For SOD, two activity peaks appeared at 1 and 3 days after BHT treatment. Subsequently, three enzyme activities sharply decreased after the peaks in BHT-treated fruits; however, the enzyme activities remained significantly $(P<0.05)$ higher than those in the control fruits during the storage.

Malondialdehyde, a marker for monitoring lipid peroxidation caused by oxidative damage, was determined in four treatments and shown in Figure 3D. The MDA content in BHT-treated fruits still had no significant $(P>0.05)$ differences compared with that in the control fruits during the storage. Inoculation with B. dothidea resulted in a sharp rise of MDA content in apple fruits from $2 \mathrm{dpi}$, and the increase of MDA content was up to 197.77\% and $251.86 \%$ more than the control at 4 and $7 \mathrm{dpi}$, respectively. However, MDA content in BHT plus B. dothidea-treated fruits increased slightly, and the enhancement was only 25.81 and $84.30 \%$ more than that of the control at 4 and $7 \mathrm{dpi}$, respectively. 


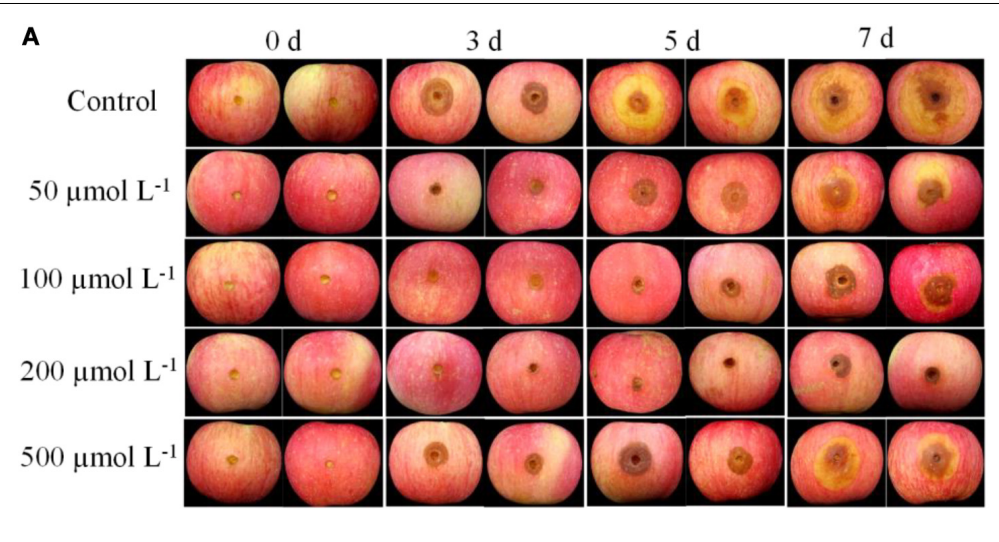

B

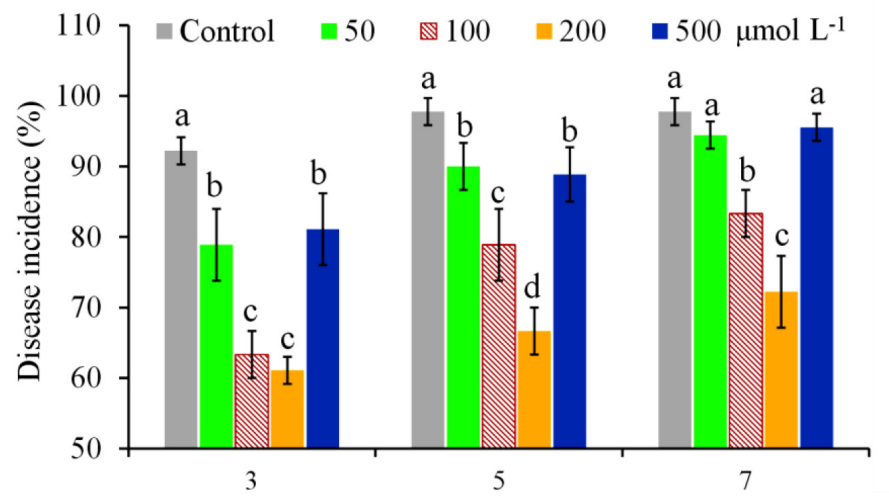

C

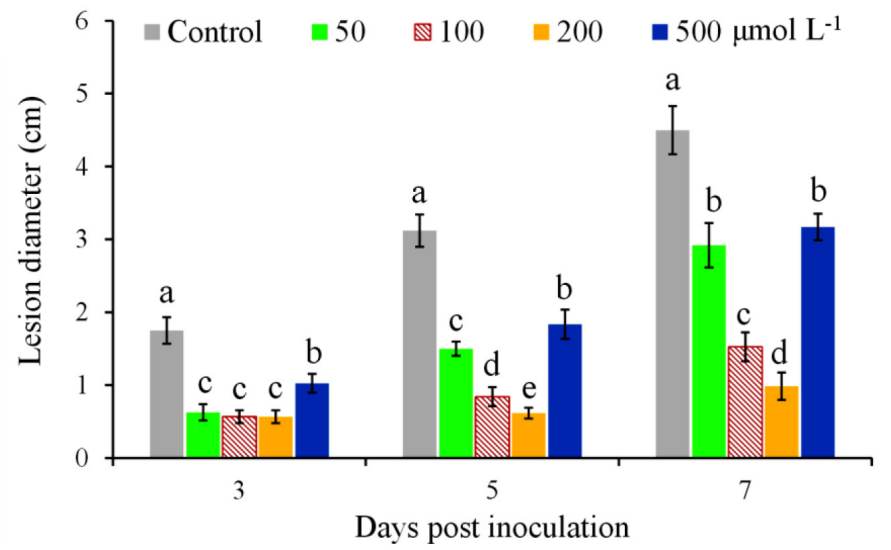

FIGURE 1 | Induced resistance at different butylated hydroxytoluene (BHT) concentrations against Botryosphaeria dothidea in apple fruits during postharvest

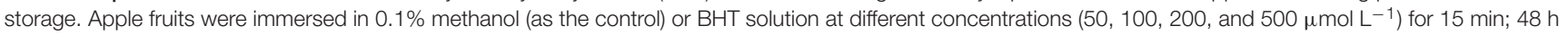
after the treatment, all fruits were inoculated with $10 \mu \mathrm{l}$ of $\mathrm{B}$. dothidea conidia suspension $\left(1 \times 10^{5}\right.$ spores $\left.\mathrm{ml}^{-1}\right)$ and then stored at $25^{\circ} \mathrm{C}$ and relative humidity (RH) of 90-95\%. Images of representative samples (A) are shown for 3, 5, and 7 days post inoculation (dpi). Changes of disease incidence (B) and lesion diameter (C) in apple fruits were measured at 3, 5, and 7 dpi. Each column represents the mean of three replicates, and vertical bars represent the standard deviation (SD). Different letters above the bars indicate statistically significant differences $(P<0.05)$ within the same panel.

\section{Effects of Butylated Hydroxytoluene on Relative Expression of Salicylic Acid/Jasmonic Acid/Ethylene Signaling Pathway Marker Genes in Apple Fruit}

To determine the activation of signaling pathways by BHT, the relative expression levels of marker genes of SA/JA/ET signaling pathway at $0,12,24$, and $48 \mathrm{~h}$ after treatment were analyzed.
PR1 and PR5 are widely used molecular markers that correlate with SA signaling activation (Zhang Y. et al., 2016). Compared with the control, BHT treatment triggered significant $(P<0.05)$ increases of $M d P R 1$ and $M d P R 5$ transcript levels during the storage (Figures 4A,B). The expression of $M d P R 1$ in BHT-treated fruits showed 4. 7-, 12.2-, and 11.8-fold increases at 12, 24, and $48 \mathrm{~h}$, respectively, when compared with that in the control fruits (Figure 4A). Meanwhile, a similar pattern was observed in the 

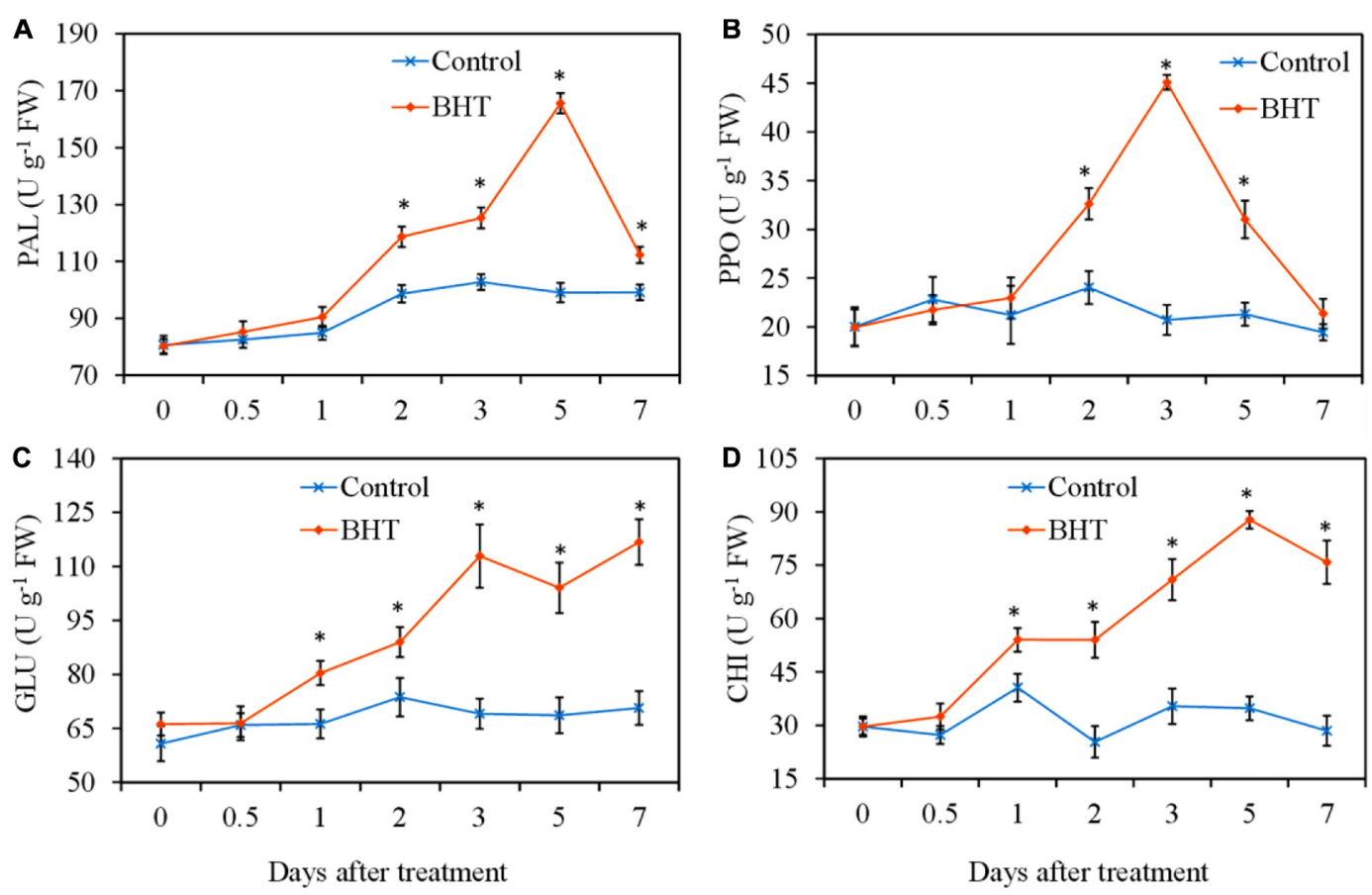

FIGURE 2 | Effects of $200 \mu \mathrm{mol} \mathrm{L} \mathrm{L}^{-1}$ of butylated hydroxytoluene (BHT) on the activities of phenylalanine ammonia lyase (PAL) (A), polyphenol oxidase (PPO) (B), $\beta$-1,3-glucanase (GLU) (C), and chitinase (CHI) (D) in apple fruits. The fruits were incubated for various time intervals at $25^{\circ} \mathrm{C}$ after $\mathrm{BHT}$ treatment. Each data point represents the mean $\pm \mathrm{SD}$ of three replicates. Asterisks denote significant difference from control at a given time point $(P<0.05)$.
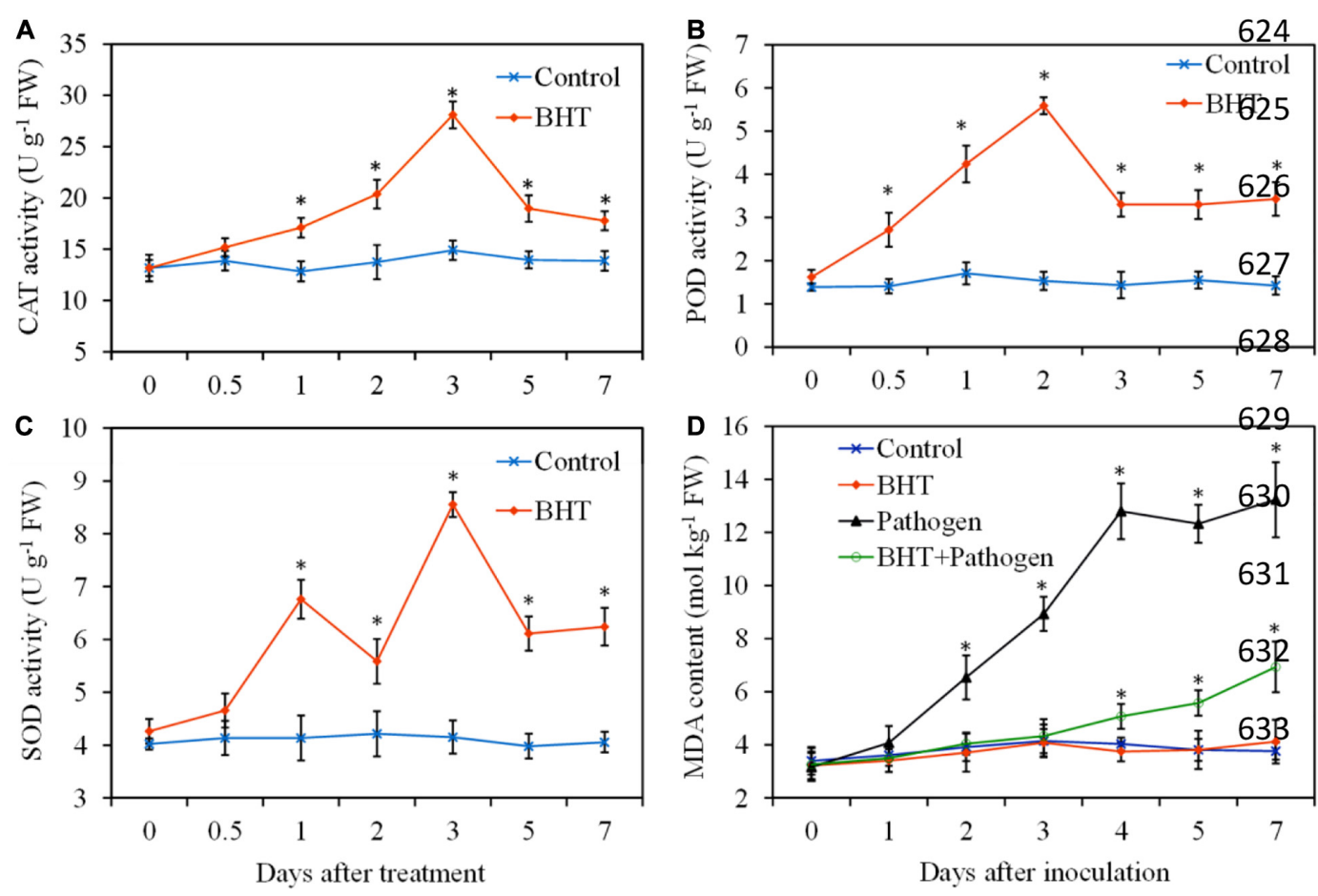

FIGURE 3 | Effects of $200 \mu \mathrm{mol} \mathrm{L}{ }^{-1}$ of butylated hydroxytoluene (BHT) on catalase (CAT) (A), superoxide dismutase (SOD) (B), and peroxidase (POD) (C) activities and lipid peroxidation as measured by malondialdehyde (MDA) content (D) in apple fruits. The fruits were incubated for various time intervals at $25^{\circ} \mathrm{C}$. Each data point represents the mean $\pm \mathrm{SD}$ of three replicates. Asterisks denote significant difference from control at a given time point $(P<0.05)$. 

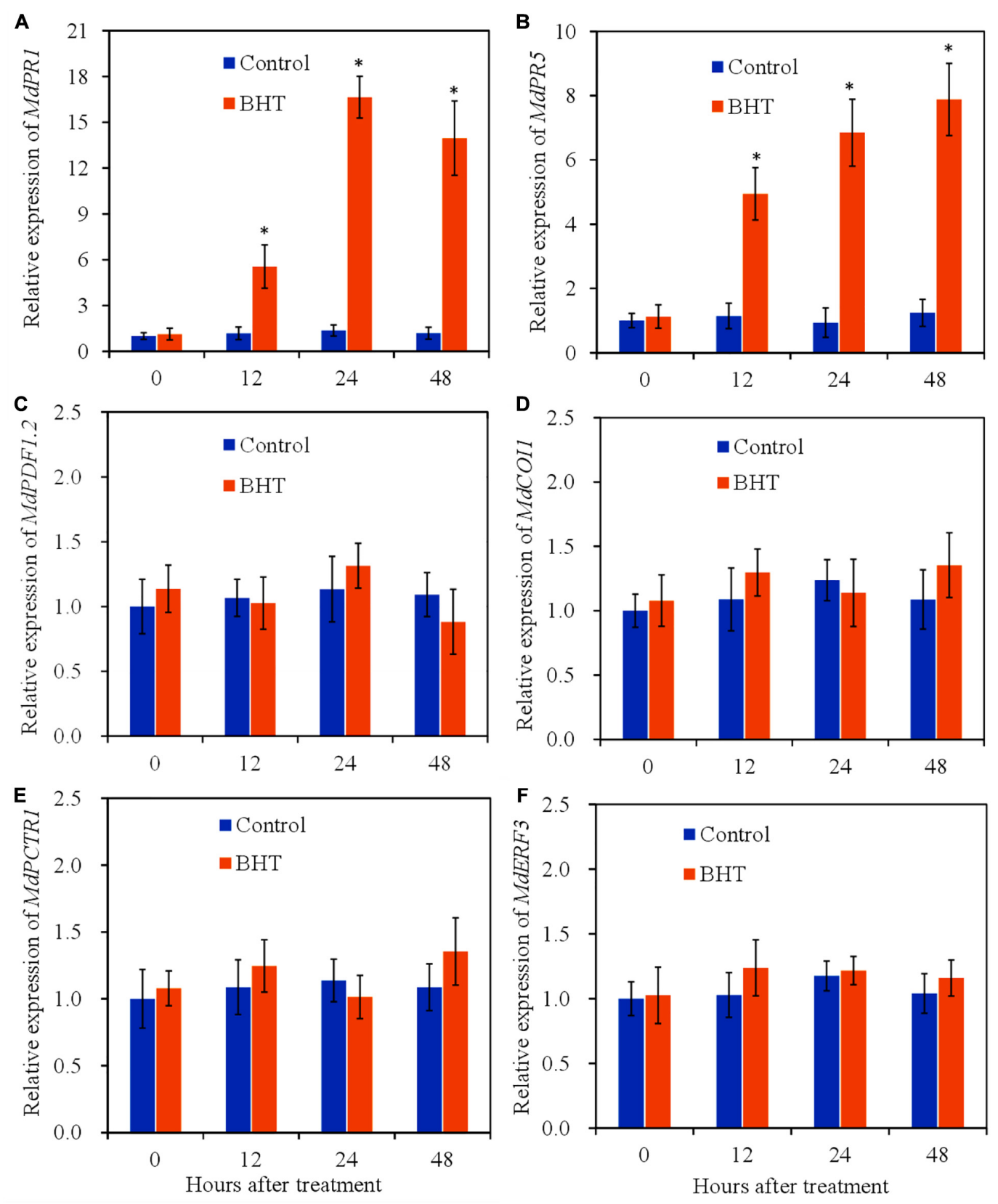

FIGURE 4 | Effects of $200 \mu \mathrm{mol} \mathrm{L}{ }^{-1}$ of butylated hydroxytoluene (BHT) on salicylic acid/jasmonic acid/ethylene (SA/JA/ET) signaling-related gene expressions in apple fruits: (A) MdPR1, (B) MdPR5, (C) MdPDF1.2, (D) MdCOI1, (E) MdCTR1, and (F) MdERF3. The fruits were incubated for various time intervals at 25 ${ }^{\circ} \mathrm{C}$. Each bar represents the mean $\pm \mathrm{SD}$ of three biological replicates. Asterisks denote significant difference from control at a given time point $(P<0.05)$.

expression of MdPR5 in BHT-treated fruits, which were 4. 3-, 7. 4-, and 6.4-fold higher than that in the control fruits.

PDF1.2 (plant defensin 1.2), which encodes an antifungal peptide, is reported to be induced by pathogen and is required for the activation of JA response pathway (Penninckx et al., 1998). Coronatine insensitive 1 (COI1) is a JA receptor responsible for transducing JA signal to activate gene expression in JA signaling pathway (Browse, 2009). In the fruit treated with $0.1 \%$ methanol (control), no statistically significant differences
$(P>0.05)$ were observed in the two JA signaling pathway marker genes (Figures 4C,D). Meanwhile, BHT treatment also did not induce the significant enhancement of MdPDF1.2 and MdCOI1 transcript levels during the storage.

Additionally, constitutive triple response 1 (CTR1) and ET response factor 3 (ERF3) are used as marker genes of ET signaling pathway (Guo and Ecker, 2004; Vahala et al., 2013). CTR1 encodes a Raf-like protein kinase and functions as a negative regulator in ET signaling pathway, while ERF3 is induced in 
plants exposed to ET. As shown in Figures 4E,F, the expression profile of CTR1 and ERF3 exhibited a similar pattern in BHTtreated fruits. BHT treatment could not trigger the up-regulation of the two ET signaling pathway marker genes. These results together suggested that BHT treatment might mainly up-regulate SA signaling pathway.

\section{Effects of Butylated Hydroxytoluene on Salicylic Acid Content and Salicylic Acid Synthesis-Related Gene Expressions in Apple Fruit}

To investigate the regulation of SA signaling pathway mediated by BHT in apple fruits, SA content and relative expression of three genes related to SA biosynthesis were analyzed, with or without BHT treatment. The free SA content and SAG level changed slightly in the control apple fruits during the storage; however, free SA and SAG contents increased remarkably in BHT-treated fruits at 12 and $24 \mathrm{~h}$, respectively (Figures 5A,B). Free SA and SAG levels continued to accumulate; and at $48 \mathrm{~h}$, the levels were 3.2- and 2.3-fold higher than those in the control fruits, respectively.

SID2 (SA induction deficient 2), PAD4 (phytoalexin deficient 4 ), and EDS1 (enhanced disease susceptibility 1) are genes related to SA biosynthesis (Dempsey et al., 2011). The relative expression of MdSID2 in the control fruits exhibited no obvious change during the storage, while the transcript levels of MdSID2 in BHT-treated fruits increased significantly $(P<0.05)$ at 24 and $48 \mathrm{~h}$ (Figure 5C). Similarly, BHT treatment up-regulated the expression of MdPAD4 and MdEDS1 during the storage. The transcript levels of MdPAD4 and MdEDS1 in BHT-treated fruits reached the highest at 24 and $48 \mathrm{~h}$, which were 3.3- and 3.4-fold higher than those in the control fruits (Figures 5D,E).

\section{DISCUSSION}

As a promising alternative to synthetic chemical fungicides in managing plant diseases, many plant activators have been widely explored for their potential application, especially in controlling postharvest diseases (Worrall et al., 2012; Liu et al., 2019). In the past two decades, there has been growing interest in finding novel plant activators to meet the requirements of plant diseases controlling (Du et al., 2012). BHT is a most commonly used antioxidant in food containing fats, pharmaceuticals, etc. (Yehye et al., 2015). Furthermore, it has been found that BHT is effective as an antioxidant with radical-scavenging activity in living systems (Fujisawa et al., 2004). However, little knowledge was available regarding the effect of BHT applied for postharvest disease control. In the present study, our data showed the excellent efficacy of BHT to control postharvest apple ring rot. Especially, we investigated the mechanism of BHT induced
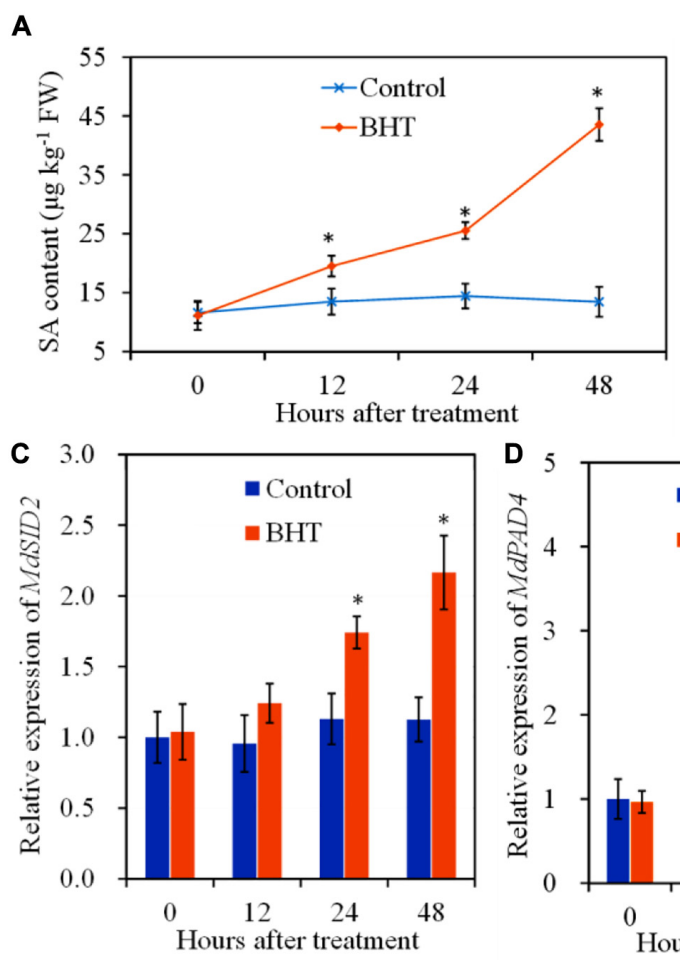
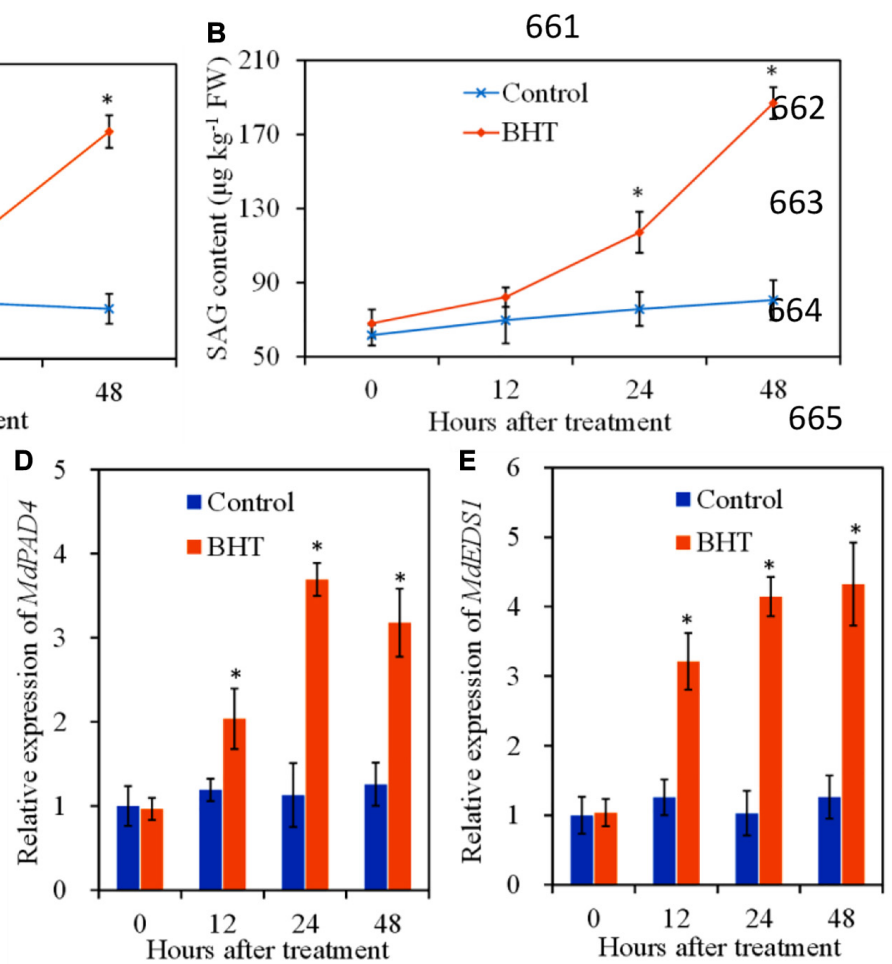

FIGURE 5 | Effects of $200 \mu \mathrm{mol} \mathrm{L}{ }^{-1}$ of butylated hydroxytoluene (BHT) on salicylic acid (SA) contents and SA synthesis-related gene expressions in apple fruits: (A) SA content; (B) SA glucoside (SAG) content; (C) MdSID2, (D) MdPAD4, and (E) MdEDS1. The fruits were incubated for various time intervals at 25 ${ }^{\circ} \mathrm{C}$. Each bar represents the mean $\pm \mathrm{SD}$ of four replicates. Asterisks denote significant difference from control $(P<0.05)$ at a given time point. 
resistance against Botryosphaeria dothidea infection and found that SA signaling pathway was associated with BHT-mediated defense response in apple fruits.

To further study BHT-induced resistance in apple fruits against $B$. dothidea, we applied different concentrations of BHT by immersion of apple fruits and evaluated the effects of BHT on disease incidence and disease severity as measured by lesion diameter. As shown in Figure 1, BHT applied by immersion of fruits at $50 \sim 500 \mu \mathrm{mol} \mathrm{L}{ }^{-1}$ could effectively reduce disease incidence and lesion diameter as compared with the control, indicating that BHT played a positive role in apple fruits against $B$. dothidea. However, the inhibitory efficiency of BHT against $B$. dothidea did not depend on the dose. The disease incidence and lesion diameter on the fruits treated with $500 \mu \mathrm{mol} \mathrm{L} \mathrm{L}^{-1}$ of BHT were significantly higher than those on the fruits treated with $100 \sim 200 \mu \mathrm{mol} \mathrm{L}{ }^{-1}$ of BHT. These results are consistent with previous reports that showed that the high doses of melatonin and L-arginine used on tomato had lower control efficiency against Botrytis cinerea than had low-dose compounds (Zheng et al., 2011; Liu et al., 2019). In addition, Zhao et al. (2018) reported that a high dose of BHT could affect the physiological response of Haematococcus pluvialis, which significantly decreased biomass production and astaxanthin content (Zhao et al., 2018). In this study, we speculate that $500 \mu \mathrm{mol} \mathrm{L}{ }^{-1}$ of BHT may cause cytotoxic effects on apple fruits, while it needs to be further confirmed. Because fruits treated with $200 \mu \mathrm{mol} \mathrm{L}{ }^{-1}$ of BHT had the least severe decay, we chose $200 \mu \mathrm{mol} \mathrm{L}{ }^{-1}$ of BHT immersion treatment to further investigate the mechanism of $\mathrm{BHT}$-induced resistance against B. dothidea. Furthermore, we found that $200 \mu \mathrm{mol} \mathrm{L}^{-1}$ of BHT had no effect on the color and sugar content of apple fruits (data not published). In the previous work, BHT applied by adding to fruit wounds at $50 \sim 1,000 \mu \mathrm{mol} \mathrm{L^{-1 }}$ could significantly reduce lesion size, and BHT at $100 \mu \mathrm{mol} \mathrm{L}{ }^{-1}$ was the most effective (Yu et al., 2018). Different methods of applying BHT may account for the inconsistency in these two studies.

The protection of plants from invasion by pathogens is largely dependent on the activation of a highly coordinated defense response. PAL, PPO, GLU, and $\mathrm{CHI}$, the primary defensive enzymes, play important roles in plant defense responses against fungal infection and are widely used as markers to assess induced resistance (Zhang Q. M. et al., 2016; Liu et al., 2019). PAL is a key enzyme in the phenylpropanoid pathway that is involved in the biosynthesis of many compounds related to the structure and resistance of plants, such as lignin and SA, whereas PPO catalyzes the oxidation of phenolic compounds to produce antimicrobial substances (Tian et al., 2006). GLU and CHI encoded by PR2 and $P R 3$ can directly inhibit fungal growth through the degradation of fungal cell walls or release oligosaccharide elicitors and induce a consequent chain of defense reactions (Edreva, 2005). Zheng et al. (2011) showed that the activities of these four enzymes in tomato fruits were trigged by L-arginine application, which induced resistance against $B$. cinerea. Zhang Y. et al. (2016) demonstrated that SA treatment increased PAL and PPO activities and up-regulated the expression of GLU and CHI in apple leaves, resulting in significantly enhanced host resistance against Glomerella cingulata infection. Our present study showed that the four defensive enzymes are important components in BHT-treated fruits, which exhibited significant higher enzyme activities than the control $(P<0.05)$. In addition, our results also indicated that BHT treatment could enhance SA levels in apple fruits. These results suggested that BHT could regulate the phenylpropanoid pathway and stimulate the production of antimicrobial substances, which in turn contribute to the induced resistance in apple fruits against $B$. dothidea.

CAT, POD, and SOD are important antioxidant enzymes that regulate the metabolism of ROS and induce resistance in fruits against pathogen invasion (Mittler, 2002). A previous study showed that BHT has significant effect on the activities of these antioxidant enzymes, which is involved in mitigating abiotic stress-induced ROS and metabolite accumulation in $H$. pluvialis (Zhao et al., 2018). In the present study, the activities of CAT, POD, and SOD in BHT-treated fruits were remarkably increased and maintained at higher levels than those in the control fruits during the storage. Correspondingly, in BHT plus $B$. dothidea-treated fruits, the capacity of fruit tissues to scavenge redundant ROS was stimulated, and MDA content remained at a lower level than that in the fruits inoculated with $B$. dothidea alone. These results indicated that high activities of antioxidant enzymes induced by BHT played critical roles in alleviating oxidative stress, which agrees with previous reports (Tareen et al., 2012; Zhang et al., 2018). Additionally, recent research demonstrated that SA treatment could enhance fruit resistance against $B$. dothidea by magnifying the activities of CAT, POD, and SOD (Zhao et al., 2020). Our results also indicated that BHT induced resistance in apple fruits is partially due to the increased activities of antioxidant enzymes.

Salicylic acid, jasmonic acid, and ethylene are critical regulatory signals in plant defense against pathogens, and these signaling pathways are also known to crosstalk in antagonistic or synergistic manners (Mundy et al., 2006). Previous studies showed that SA is involved in the principal pathway in apple fruits to fight against $B$. dothidea, and exogenous SA application could enhance the resistance to $B$. dothidea in apple fruits (Zhao et al., 2020). In our study, PR1 and PR5 were strongly induced by BHT in apple fruits, indicating that effective manipulation of SA signaling pathway was essential for fruit resistance conferred by BHT treatment. The transcripts of PDF1.2 and COI1, as well as CTR1 and ERF3, were not induced by BHT, suggesting that JA and ET may be not the main signaling pathways in the BHT-induced resistance. Various studies demonstrated that JA signaling pathway is primarily induced by and effective in resistance against necrotrophic pathogens (Trusov et al., 2006). For example, melatonin induced resistance against $B$. cinerea in tomato fruits by stimulating JA signaling pathway (Liu et al., 2019). Moreover, the synergistic effects of JA and ET signaling pathways are reported to inhibit gray mod in tomato fruits (Yu et al., 2019).

Salicylic acid content and SA synthesis-related gene expression were also determined in this study, which helped us to further determine whether SA signaling pathway mediated the BHTinduced resistance in apply fruits against $B$. dothidea. SID2 plays an essential role in SA accumulation and plant disease resistance (Dempsey et al., 2011). In apple fruits, MdSID2 contributed to the 
production of SA against B. dothidea infection (Zhao et al., 2020). EDS1 and its interacting partner, $P A D 4$, constitute a regulatory hub that is essential in the regulation of the plant defense to invasive (hemi-)biotrophic pathogens (Wiermer et al., 2005). Based on our results, the expression levels of SID2, PAD4, and EDS1 were up-regulated significantly; and SA content increased remarkably in BHT-treated fruits, which led us to conclude that BHT-induced resistance against apple ring rot was mainly through the accumulation of SA content.

\section{CONCLUSION}

Butylated hydroxytoluene treatment triggered remarkable disease resistance against apple ring rot caused by Botryosphaeria dothidea. BHT could enhance the activities of defensive enzymes CHI, GLU, PAL, and PPO. Meanwhile, it increased antioxidant enzyme activities to alleviate lipid peroxidation. Furthermore, BHT treatment promoted SA content and up-regulated SA defense signaling, which is a crucial pathway in pathogen resistance. These data indicate that BHT confers resistance in apple fruits against $B$. dothidea, possibly by increasing defensive enzyme activities and activating SA signaling pathway. Therefore, our study strongly supports the application of BHT as a new plant activator to inhibit postharvest decay caused by $B$. dothidea in apple fruits.

\section{REFERENCES}

Babich, H. (1982). Butylated hydroxytoluene (BHT): a review. Environ. Res. 29, 1-29. doi: 10.1016/0013-9351(82)90002-0

Browse, J. (2009). Jasmonate passes muster: a receptor and targets for the defense hormone. Annu. Rev. Plant Biol. 60, 183-205. doi: 10.1146/annurev.arplant. 043008.092007

Dempsey, D. M. A., Vlot, A. C., Wildermuth, M. C., and Klessig, D. F. (2011). Salicylic acid biosynthesis and metabolism. Arabidopsis Book 9:e0156. doi: 10. 1199/tab.0156

Du, Q., Zhu, W., Zhao, Z., Qian, X., and Xu, Y. (2012). Novel benzo-1,2,3thiadiazole-7-carboxylate derivatives as plant activators and the development of their agricultural applications. J. Agric. Food Chem. 60, 346-353. doi: 10.1021/ jf203974p

Edreva, A. (2005). Pathogenesis related proteins: research progress in the last 15 years. Gen. Appl. Plant Physiol. 31, 105-124.

Fan, K., Wang, J., Fu, L., Li, X., Zhang, Y., Zhang, X., et al. (2016). Sensitivity of Botryosphaeria dothidea from apple to tebuconazole in China. Crop Prot. 87, 1-5. doi: 10.1016/j.cropro.2016.04.018

Fan, K., Wang, J., Fu, L., Zhang, G. F., Wu, H. B., Feng, C., et al. (2018). Baseline sensitivity and control efficacy of pyraclostrobin against Botryosphaeria dothidea isolates in China. Plant Dis. 103, 1458-1463. doi: 10.1094/PDIS-0718-1214-RE

Fujisawa, S., Kadoma, Y., and Yokoe, I. (2004). Radical-scavenging activity of butylated hydroxytoluene (BHT) and its metabolites. Chem. Phys. Lipids 130, 189-195. doi: 10.1016/j.chemphyslip.2004.03.005

Glazebrook, J. (2005). Contrasting mechanisms of defense against biotrophic and necrotrophic pathogens. Annu. Rev. Phytopathol. 43, 205-227. doi: 10.1146/ annurev.phyto.43.040204.135923

Guo, H., and Ecker, J. R. (2004). The ethylene signaling pathway: new insights. Curr. Opin. Plant Biol. 7, 40-49. doi: 10.1016/j.pbi.2003.11.011

Leng, W. F., Li, B. H., Guo, L. Y., Dong, J. H., Wang, C. X., Li, G. F., et al. (2009). Method to promote sporulation of Botryosphaeria berengeriana $\mathrm{f}$. sp. piricola. Acta Phytopathol. Sinica 39, 536-539. doi: 10.13926/j.cnki.apps.2009.05.017

\section{DATA AVAILABILITY STATEMENT}

The original contributions presented in the study are included in the article/supplementary material, further inquiries can be directed to the corresponding author.

\section{AUTHOR CONTRIBUTIONS}

$\mathrm{YH}$ and CS carried out the experiments and analyzed the data with the help of XG and SL. SL analyzed the data of gene expression and prepared the figure. $\mathrm{YH}$ and $\mathrm{CW}$ wrote the manuscript with help from all authors. BL performed the manuscript revision and provided part of the financial support. $\mathrm{XG}$ reviewed and edited the manuscript. All authors approved its final version.

\section{FUNDING}

The authors thank the financial support from projects of the Shandong Provincial Primary Research and Development Plan (No. 2019GSF109061), Qingdao Science and Technology Benefit People Demonstration and Guidance Project (No. 20-3-4-23nsh), National Key Research and Development Project (No. 2016YFD0201122), and Chinese Modern Agricultural Industry Technology System (No. CARS-28).

Liu, C., Chen, L., Zhao, R., Li, R., Zhang, S., Yu, W., et al. (2019). Melatonin induces disease resistance to Botrytis cinerea in tomato fruit by activating jasmonic acid signaling pathway. J. Agric. Food Chem. 67, 6116-6124. doi: 10.1021/acs.jafc. $9 \mathrm{~b} 00058$

Marschall, R., and Tudzynski, P. (2016). Reactive oxygen species in development and infection processes. Semin. Cell Dev. Biol. 57, 138-146. doi: 10.1016/j. semcdb.2016.03.020

Mittler, R. (2002). Oxidative stress, antioxidants and stress tolerance. Trends Plant Sci. 7, 405-410. doi: 10.1016/S1360-1385(02)02312-9

Mundy, J., Nielsen, H. B., and Brodersen, P. (2006). Crosstalk. Trends Plant Sci. 11, 63-64. doi: 10.1016/j.tplants.2005.12.003

Penninckx, I. A. M. A., Thomma, B. P. H. J., Buchala, A., Métraux, J. P., and Broekaert, W. F. (1998). Concomitant activation of jasmonate and ethylene response pathways is required for induction of a plant defensin gene in Arabidopsis. Plant Cell 10:2103-2113. doi: 10.2307/38 70787

Tang, W., Ding, Z., Zhou, Z. Q., Wang, Y. Z., and Guo, L. Y. (2012). Phylogenetic and pathogenic analyses show that the causal agent of apple ring rot in China is Botryosphaeria dothidea. Plant Dis. 96, 486-496. doi: 10.1094/PDIS-08-110635

Tareen, M. J., Abbasi, N. A., and Hafiz, I. A. (2012). Postharvest application of salicylic acid enhanced antioxidant enzyme activity and maintained quality of peach cv. 'Flordaking' fruit during storage. Sci. Hortic. 142, 221-228. doi: 10.1016/j.scienta.2012.04.027

Tian, S., Wan, Y., Qin, G., and Xu, Y. (2006). Induction of defense responses against Alternaria rot by different elicitors in harvested pear fruit. Appl. Microbiol. Biotechnol. 70, 729-734. doi: 10.1007/s00253-0050125-4

Torres, M. A. (2010). ROS in biotic interactions. Physiol. Plantarum 138, 414-429. doi: 10.1111/j.1399-3054.2009.01326.x

Trusov, Y., Rookes, J. E., Chakravorty, D., Armour, D., Schenk, P. M., and Botella, J. R. (2006). Heterotrimeric G proteins facilitate Arabidopsis resistance to necrotrophic pathogens and are involved in jasmonate signaling. Plant Physiol. 140, 210-220. doi: 10.1104/pp.105.069625 
Vahala, J., Felten, J., Love, J., Gorzsás, A., Gerber, L., Lamminmäki, A., et al. (2013). (ERFs) in hybrid aspen stem identifies ERF genes that modify stem growth and wood properties. New Phytol. 200, 511-522. doi: 10.1111/nph.12386

Van Bockhaven, J., Spíchal, L., Novák, O., Strnad, M., Asano, T., Kikuchi, S., et al. (2015). Silicon induces resistance to the brown spot fungus Cochliobolus miyabeanus by preventing the pathogen from hijacking the rice ethylene pathway. New Phytol. 206, 761-773. doi: 10.1111/nph.13270

Verberne, M. C., Brouwer, N., Delbianco, F., Linthorst, H. J. M., and Verpoorte, R. (2002). Method for the extraction of the volatile compound salicylic acid from tobacco leaf material. Phytochem. Anal. 13, 45-50. doi: 10.1002/pca.615

Wang, C. X., El-Shetehy, M., Shine, M. B., Yu, K. S., Navarre, D., Wendehenne, D., et al. (2014). Free radicals mediate systemic acquired resistance. Cell Rep. 7, 348-355. doi: 10.1016/j.celrep.2014.03.032

Wiermer, M., Feys, B. J., and Parker, J. E. (2005). Plant immunity: the EDS1 regulatory node. Curr. Opin. Plant Biol. 8, 383-389. doi: 10.1016/j.pbi.2005.05. 010

Worrall, D., Holroyd, G. H., Moore, J. P., Glowacz, M., Croft, P., Taylor, J. E., et al. (2012). Treating seeds with activators of plant defence generates longlasting priming of resistance to pests and pathogens. New Phytol. 193, 770-778. doi: 10.1111/j.1469-8137.2011.03987.x

Yang, J., Sun, C., Zhang, Y., Fu, D., Zheng, X., and Yu, T. (2017). Induced resistance in tomato fruit by $\gamma$-aminobutyric acid for the control of alternaria rot caused by Alternaria alternata. Food Chem. 221, 1014-1020. doi: 10.1016/j.foodchem. 2016.11.061

Yang, Q., Zhang, H., Zhang, X., Zheng, X., and Qian, J. (2015). Phytic acid enhances biocontrol activity of Rhodotorula mucilaginosa against Penicillium expansum contamination and patulin production in apples. Front. Microbiol. 6:1296. doi: 10.3389/fmicb.2015.01296

Yehye, W. A., Rahman, N. A., Ariffin, A., Abd Hamid, S. B., Alhadi, A. A., Kadir, F. A., et al. (2015). Understanding the chemistry behind the antioxidant activities of butylated hydroxytoluene (BHT): a review. Eur. J. Med. Chem. 101, 295-312. doi: 10.1016/j.ejmech.2015.06.026

Yu, C., Zeng, L., Sheng, K., Chen, F., Zhou, T., Zheng, X., et al. (2014). $\gamma$ aminobutyric acid induces resistance against Penicillium expansum by priming of defence responses in pear fruit. Food Chem. 159, 29-37. doi: 10.1016/j. foodchem.2014.03.011

Yu, C. L., Meng, L. L., Lian, S., Li, B. H., Liang, W. X., and Wang, C. X. (2018). Control efficiency of BHT against apple fruit ring rot and its influence on the activity of defensive enzymes. Plant Physiol. J. 54, 819-826. doi: 10.13592/j.cnki. ppj.2018.0016
Yu, W., Yu, M., Zhao, R., Sheng, J., Li, Y., and Shen, L. (2019). Ethylene perception is associated with methyl-jasmonate-mediated immune response against Botrytis cinerea in tomato fruit. J. Agric. Food Chem. 67, 6725-6735. doi: 10.1021/acs.jafc.9b02135

Zhang, M., Liu, M., Pan, S., Pan, C., Li, Y., and Tian, J. (2018). Perillaldehyde controls postharvest black rot caused by Ceratocystis fimbriata in sweet potatoes. Front. Microbiol. 9:1102. doi: 10.3389/fmicb.2018.01102

Zhang, Q. M., Yong, D. J., Zhang, Y., Shi, X. P., Li, B. H., Li, G. F., et al. (2016). Streptomyces rochei A-1 induces resistance and defense-related responses against Botryosphaeria dothidea in apple fruit during storage. Postharvest Biol. Tec. 115, 30-37. doi: 10.1016/j.postharvbio.2015.12.013

Zhang, Y., Shi, X. P., Li, B. H., Zhang, Q. M., Liang, W. X., and Wang, C. X. (2016). Salicylic acid confers enhanced resistance to Glomerella leaf spot in apple. Plant Physiol. Bioch. 106, 64-72. doi: 10.1016/j.plaphy.2016.04.047

Zhao, X., Qi, C., Jiang, H., Zhong, M., You, C., Li, Y., et al. (2020). MdWRKY15 improves resistance of apple to Botryosphaeria dothidea via the salicylic acidmediated pathway by directly binding the MdICS1 promoter. J. Integr. Plant Biol. 62, 527-543. doi: 10.1111/jipb.12825

Zhao, X., Zhang, G. L., Li, B. H., Xu, X. M., Dong, X. L., Wang, C. X., et al. (2016). Seasonal dynamics of Botryosphaeria dothidea infections and symptom development on apple fruits and shoots in China. Eur. J. Plant Pathol. 146, 507-518. doi: 10.1007/s10658-016-0935-5

Zhao, Y., Yue, C., Ding, W., Li, T., Xu, J. W., Zhao, P., et al. (2018). Butylated hydroxytoluene induces astaxanthin and lipid production in Haematococcus pluvialis under high-light and nitrogen-deficiency conditions. Bioresource Technol. 266, 315-321. doi: 10.1016/j.biortech.2018.06.111

Zheng, Y., Sheng, J., Zhao, R., Zhang, J., Lv, S., Liu, L., et al. (2011). Preharvest $\mathrm{L}$-arginine treatment induced postharvest disease resistance to Botrysis cinerea in tomato fruits. J. Agric. Food Chem. 59, 6543-6549. doi: 10.1021/jf2000053

Conflict of Interest: The authors declare that the research was conducted in the absence of any commercial or financial relationships that could be construed as a potential conflict of interest.

Copyright (c) 2021 Huang, Sun, Guan, Lian, Li and Wang. This is an open-access article distributed under the terms of the Creative Commons Attribution License (CC BY). The use, distribution or reproduction in other forums is permitted, provided the original author(s) and the copyright owner(s) are credited and that the original publication in this journal is cited, in accordance with accepted academic practice. No use, distribution or reproduction is permitted which does not comply with these terms. 